\title{
Crisis Intervention for People With Severe Mental Illnesses
}

\author{
Suzanne Murphy ${ }^{1, *}$, Claire B. Irving ${ }^{2}$, Clive E. Adams ${ }^{2}$, and Ron Driver ${ }^{1}$ \\ ${ }^{1}$ NIHR East of England Research Design Services, University of Bedfordshire, Luton, Bedfordshire, UK; ${ }^{2}$ Cochrane Schizophrenia \\ Group, The University of Nottingham, Nottingham, UK \\ *To whom correspondence should be addressed; University of Bedfordshire, Putteridge Bury campus, Hitchin Road, Luton, \\ Bedfordshire, LU2 8LE, UK; tel: +44 (0)1582-743461, fax: +44 (0)1582-743918, e-mail: suzanne.murphy@beds.ac.uk
}

Key words: schizophrenia/severe mental illness/crisis intervention/Cochrane systematic review/meta-analysis/ randomized controlled trials

\section{Background}

Severe psychiatric illnesses are phasic. After initial treatment, people with schizophrenia or other similar disorders usually experience long periods of relative stability. Relapses or crises can, however, occur for reasons such as exposure to environmental stressors or complications with medication. Crisis intervention care was developed to treat psychiatric crises in the home or a home-like environment usually as an alternative to admission to a psychiatric hospital.

\section{Objective}

To assess the effectiveness of crisis intervention compared with standard treatment, the latter generally being hospitalization.

\section{Search Methods}

We searched the Cochrane Schizophrenia Group Trials Register (March 2010), which is compiled by systematic searches of major databases, hand searches, and conference proceedings, inspected references of all identified studies (included and excluded), and contacted first authors for additional data.

\section{Selection Criteria}

We included all relevant randomized controlled trials (RCTs) reporting on crisis interventions for severe mental illnesses: home-based crisis interventions or crisis interventions based in residential community settings. We excluded quasi-randomized trials.

\section{Data Collection and Analysis}

Data were extracted from included articles by two independent reviewers. Authors of trials were contacted for additional and missing data. Relative risks (RRs) and 95\% confidence intervals (CIs) of homogeneous dichotomous data were calculated. A random-effects model was used for heterogeneous dichotomous data. Weighted means were calculated for continuous data.

\section{Results}

A total of 1144 participants were included from 8 trials conducted between 1964 and 2010 (mean study duration $\sim 12$ months, range 3-24 months, risk of bias: high to moderate). Admission into hospital in the 6 months after the initial crisis was lower in participants who had received crisis intervention as opposed to treatment as usual ( $n=369$, 2 RCTs, RR 0.75, 95\% CI 0.50-1.13) (figure 1). Overall, the number of deaths was small and similar for both groups $(n=980,6$ RCTs, RR $0.88,95 \%$ CI 0.37-2.07). Likewise, the number of attempted suicides for both groups was very similar ( $n=369,3 \mathrm{RCTs}$, RR 2.62, 95\% CI 0.21-32.02). Six months after crisis, the number of families of participants stating that the burden of care was great was significantly lower for those who had received crisis intervention than for those who had received standard care $(n=120,1$ RCT, RR 0.34, 95\% CI 0.20-0.59). Use of the Client Satisfaction Questionnaire (CSQ-8) at 20 months' follow-up also indicated that patient satisfaction was significantly higher in the crisis intervention group $(n=137,1$ RCT, MD 5.4, 95\% CI 3.91-6.89) (figure 1).

\section{Conclusions}

Taken together, these results paint a promising picture for the effectiveness of crisis intervention packages and their acceptability to both patients and their families. However, the quality of the evidence collected in this review is, at 


\begin{tabular}{|c|c|c|c|c|c|c|c|c|}
\hline \multirow[b]{2}{*}{ Study or Subgroup } & \multicolumn{2}{|c|}{ CRISIS } & \multicolumn{2}{|c|}{ STANDARD } & \multirow[b]{2}{*}{ Weight } & Risk Ratio & \multirow{2}{*}{\multicolumn{2}{|c|}{$\begin{array}{c}\text { Risk Ratio } \\
\text { M-H, Random, } 95 \% \mathrm{Cl}\end{array}$}} \\
\hline & Events & Total & Events & Total & & $\mathrm{M}-\mathrm{H}$, Random, $95 \% \mathrm{Cl}$ & & \\
\hline \multicolumn{9}{|l|}{ 1.7.1 by 3 months } \\
\hline Johnson 2005 & 49 & 135 & 86 & 125 & $100.0 \%$ & $0.53[0.41,0.68]$ & & \\
\hline Subtotal $(95 \% \mathrm{Cl})$ & & 135 & & 125 & $100.0 \%$ & $0.53[0.41,0.68]$ & & \\
\hline Total events & 49 & & 86 & & & & & \\
\hline \multicolumn{9}{|c|}{ Heterogeneity: Not applicable } \\
\hline \multicolumn{9}{|c|}{ Test for overall effect: $Z=4.96(P \leq 0.00001)$} \\
\hline \multicolumn{9}{|l|}{1.7 .2 by 6 months } \\
\hline Fenton 1998 & 37 & 63 & 30 & 48 & $46.3 \%$ & $0.94[0.70,1.27]$ & & \\
\hline Johnson 2005 & 63 & 134 & 94 & 124 & $53.7 \%$ & $0.62[0.51,0.76]$ & & \\
\hline Subtotal $(95 \% \mathrm{Cl})$ & & 197 & & 172 & $100.0 \%$ & $0.75[0.50,1.13]$ & & \\
\hline \multirow{2}{*}{\multicolumn{9}{|c|}{$\begin{array}{l}\text { Total events } \quad 100 \quad 124 \\
\text { Heterogeneity: Tau }{ }^{2}=0.07 ; \mathrm{Ch}^{\mathrm{z}}=4.99, \mathrm{df}=1(\mathrm{P}=0.03) ; \mathrm{F}^{2}=80 \% \\
\text { Test for overall effect: } \mathrm{Z}=1.38(\mathrm{P}=0.17)\end{array}$}} \\
\hline & & & & & & & & \\
\hline & & & & & & & $\begin{array}{cc}1 & 1 \\
0.2 & 0.5 \\
\text { Favours Crisis }\end{array}$ & $\begin{array}{ccc} & \frac{1}{2} & 5 \\
\text { Favours Standard }\end{array}$ \\
\hline
\end{tabular}

Fig. 1. Hospital use: repeat admissions excluding index admission.

best, moderate. Study size was small ranging from 41 to 260 and, in many cases, methodology was considerably flawed with blinding not always described and raters sometimes not independent. Studies used few measures in common making comparisons difficult. Furthermore, older studies included assessed crisis intervention as part of an on-going home-based package of care, rather than as a brief, crisis-focused treatment. A major problem in this field is the consideration of ethical issues with regard to the randomization of participants at a time of crisis. However, recent studies have overcome these challenges and can provide a model for future fruitful investigation. With the widespread implementation of crisis intervention packages in several countries, research of higher quality is urgently needed. Full details of this review are reported elsewhere. ${ }^{1}$

\section{Acknowledgments}

The authors have declared that there are no conflicts of interest in relation to the subject of this study.

\section{Reference}

1. Murphy S, Irving CB, Adams CE, Driver R. Crisis intervention for people with severe mental illnesses. Cochrane Database of Systematic Reviews. 2012;5. Art. No.: CD001087. doi: 10.1002/14651858.CD001087.pub4. 